\title{
INSTRUMENTATION PRINCIPLES FOR PERFORMANCE MEASUREMENT OF SOLAR HEATING SYSTEMS
}

\author{
NOAM LIOR \\ Department of Mechanical Engineering and Applied Mechanics, University of Pennsylvania, Philadelphia, \\ PA 19104, U.S.A.
}

(Received 1 July 1978)

\begin{abstract}
An instrumentation design and implementation plan for monitoring the performance of solar heating systems and of their components is described. Specifically the selection of the data acquisition system and of the sensors, the procurement process and installation and calibration principles are discussed in detail. As a practical example, the cost and choice of measurement methods and instruments used in the University of Pennsylvania SolaRow house is presented.
\end{abstract}

\subsection{Background and major issues}

A rapidly increasing number of systems utilizing solar heat are being installed and operated, mainly through government initiative and support. A major objective of these installations is to derive quantitative information about their performance so as to allow state of the art evaluation. This will provide a foundation for performance improvement and cost reduction of solar heating equipment and systems, thereby accelerating their widespread utilization. Due to the moderate ranges of the variables, the above measurements are not difficult. However, they do pose a number of specific problems which have not always been recognized and carefully addressed, thereby resulting in the current scarcity of performance data in general and of good data in particular (see Scovill and Gillett ${ }^{1}$ ). The most important of these problems are: (1) the significantly transient and stochastic nature of weather, insolation and heat demand, (2) the relatively small temperature differences that need to be measured, and (3) the relatively low system flow rates and wide flow range which frequently occurs in solar systems.

\subsection{Transient data}

The stochastic variables necessitate the collection and analysis of an extremely large amount of data over long periods of time, e.g. a full heating or cooling season, or a whole year. These data are presently acquired by different investigators at a variety of frequencies: continuous monitoring (such as by means of strip-chart recorders or high-speed data acquisition systems); intermittent scanning at rates such as once per minute, per $5 \mathrm{~min}$, per $15 \mathrm{~min}$, or per $\mathrm{hr}$; and long term integration which is recorded once a day, a week, a month, or a season. Long term integration provides the simplest and most economical method, but it does not provide the detailed performance data which are frequently needed for system and component evaluation. It is also virtually useless for system optimization and trouble shooting.

When continuous or frequently scanned data are acquired, expensive data acquisition systems (DAS) are needed, and data reduction must be performed by computer. Furthermore, the reliability of such equipment is usually not compatible with the requirement for its continuous use over periods of the order of one year. This requirement also imposes (1) the necessity to select highly reliable sensors, (2) the necessity to give serious consideration to the question of DAS and sensor calibration without undue interruption of system operation and measurement, (3) the need to use an uninterruptible power supply for the instrumentation system, and (4) a significant investment of skilled manpower to supervise the operation of the measurement system. The latter task includes maintenance, calibration, data collection and interpretation for a lengthy period of time on an around-the-clock alert basis. Data reduction and interpretation for a large number of installations may be handled by a single remote centralized facility (e.g. as described by Murphy ${ }^{2}$ ) and thus save time and insure uniform treatment. However, for many important and obvious reasons, the on-site experimenter is irreplaceable. 


\subsection{Measurement of small temperature differences}

Temperature differences are measured to determine:

(1) Heat gain or loss $(Q)$ of flowing fluids through a system's components between times $t_{1}$ and $t_{2}$ by means of the equation

$$
Q=\int_{t_{1}}^{t_{2}} \dot{m} c\left(T_{\text {out }}-T_{\text {in }}\right) \mathrm{d} t=\int_{t_{1}}^{t_{2}} \rho V A c \Delta T_{o i} \mathrm{~d} t
$$

where $m$, mass flow rate of fluid; $c$, specific heat of fluid; $T_{\text {out }}$, temperature of fluid at outlet; $T_{\text {in }}$, temperature of fluid at inlet; $t_{1}, t_{2}$, time integration limits; $\rho$, density of fluid; $V$, velocity of fluid; $A$, cross sectional flow area in conduit at location where $V$ is measured; $\Delta T_{o i}$, temperature difference measured between the fluid's inlet and outlet.

(2) Rates of heat exchange $(q)$, or heat transfer coefficients $(U)$ by means of the equation

$$
Q=U A\left(T_{1}-T_{2}\right)=U A \Delta T_{12}
$$

where $A$ is the heat transfer area and $\Delta T_{12}$ is the temperature difference measured across a heat transfer interface between medium No. 1 and medium No. 2.

(3) Efficiency of solar collectors to which the Hottel-Woertz equation is applicable:

$$
\eta=\dot{m} c \Delta T_{o i} / I A=F_{R}\left[(\alpha \tau)_{e}-U_{L}\left(T_{i}-T_{a}\right) / I\right]=a-b \Delta T_{i a} / I .
$$

Equation (3) shows that only the temperature differences, $\Delta T_{i a}$ and $\Delta T_{o i}$, are necessary to describe the behavior of the collector's efficiency $\eta$, where $I$, insolation flux; $F_{R}$, collector heat removal factor; $(\alpha \tau)_{e}$, effective absorptance-transmittance product of collector in solar radiation spectrum; $U_{L}$, collector's overall heat loss coefficients; $T_{a}$, ambient air temperature; $\Delta T_{i a} \equiv$ $T_{i}-T_{a}$.

Assuming that measurement of temperature $T$ is characterized by the standard deviation error $\sigma$, the relative error $\epsilon_{T}$ could be described by

$$
\epsilon_{T}=\sigma / T
$$

Now if temperature differences $\Delta T$ are measured, assuming that the errors of the two probes used are independent and have a value of $\sigma$ each, the relative standard deviation error of the temperature difference measurement, $\epsilon_{\Delta T}$, is

$$
\epsilon_{\Delta T}=(\sqrt{ } 2) \sigma / \Delta T \text {. }
$$

In a worst case situation, where the errors accumulate directly,

$$
\epsilon_{\Delta T, \max }=2 \sigma / \Delta T
$$

The error expression (5) gives values which are typically larger than those obtained from (4). The ratio of the two is

$$
\epsilon_{\Delta T T T} \equiv \epsilon_{\Delta T} / \epsilon_{T}=\sqrt{ }(2) T / \Delta T
$$

and in the worst case

$$
\left(\epsilon_{\Delta T / T}\right)_{\max } \equiv\left(\epsilon_{\Delta T} / \epsilon_{T}\right)_{\max }=2 T / \Delta T \text {. }
$$

$\epsilon_{\Delta T T}$ is plotted in Fig. 1 as a function of $\Delta T$, for $T=30,80$, and $130^{\circ} \mathrm{C}$.

Given a Coefficient of Variation $\epsilon_{T}$ for an instrument for the measurement of "absolute" temperature, Fig. 1 shows how much larger the Coefficient of Variation for temperature difference measurement (error $\epsilon_{\Delta T}$ ) is. For example, given a thermometer which has an $\epsilon_{T}$ of $1 / 2 \%$ of full scale, a system of two such thermometers used to measure a temperature difference would have a relative error $\sim 113$ times larger than that $\left(\epsilon_{\Delta T}=56.6 \%\right)$ for $\Delta T=1^{\circ} \mathrm{C}$, and an error 


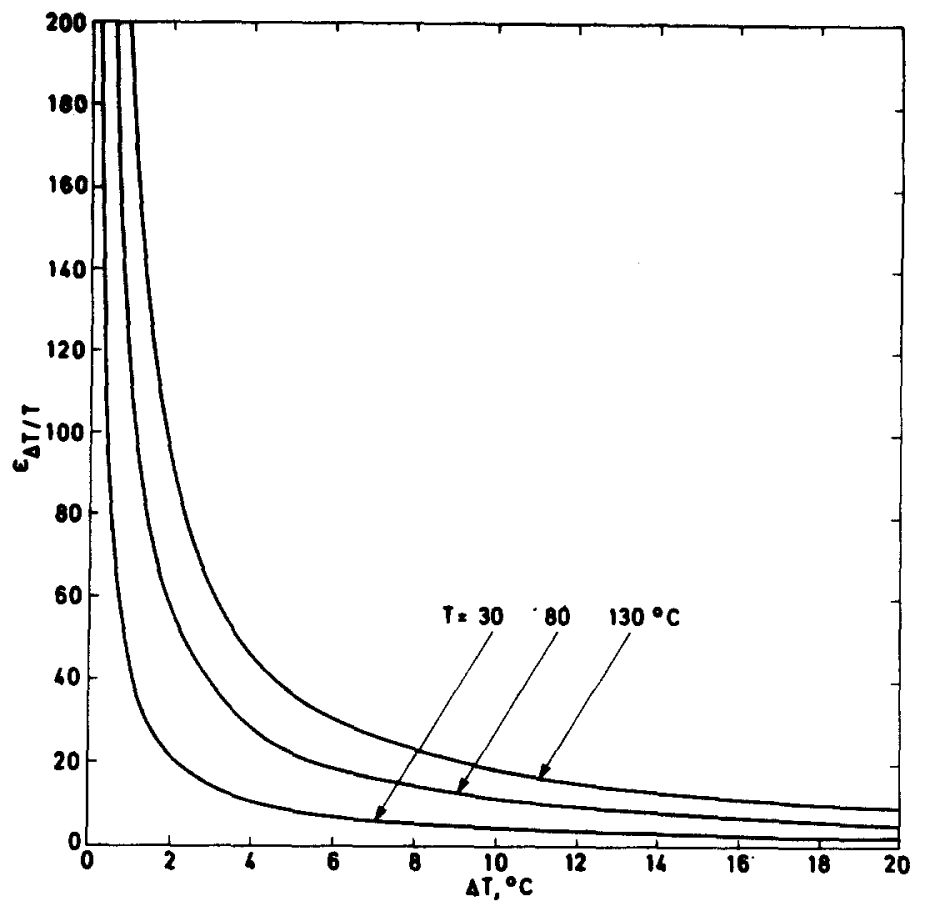

Fig. 1. The effect of small temperature differences $(\Delta T)$ on the relative error incurred by subtracting the two measurements,

$$
\epsilon_{\Delta T T} \equiv\left(\sigma_{\Delta T} / \Delta T\right) \cdot\left(\sigma_{T} / T\right)^{-1}
$$

$\sigma \equiv$ standard deviation of the measurement error.

$\sim 11$ times larger $\left(\epsilon_{\Delta T}=5.5 \%\right)$ for $\Delta T=10^{\circ} \mathrm{C}$, all at a level of $T=80^{\circ} \mathrm{C}$. Keeping in mind that the Coefficient of Variation represents only about $1 / 3$ of the total error (since $\pm 3 \sigma$ contains a probability of $99.73 \%$ ), and that the maximal error may be represented by Eqs. (6) and (8) instead of (5) and (7), the actual error may be 4.24 larger than that indicated above. Equation (5) and Fig. 1 can also be used to determine the allowed $\sigma$ of a thermometer (this is a manufacturer's specification) so that the tolerable $\epsilon_{\Delta T}$ is obtained, thereby facilitating instrument selection.

The desired quantities $Q$ and $\eta$ in Eqs. (1)-(3) depend linearly on their respective $\Delta T$ values, and thus any error incurred in $\Delta T$ measurement is impressed directly on those final results. This indicates the importance of reducing these errors by the proper selection of instruments or measurement techniques.

Several techniques can be used to improve the accuracy of $\Delta T$ measurement. Probably the most straightforward is to perform two measurements of $\Delta T$, exchanging the positions of the two thermometers for the second measurement. This eliminates the major effect of an offset error between the two probes, but is not easy to implement mechanically and is ineffective under the transient conditions incurred with solar heating and cooling systems. A more practical and applicable technique is to employ a measurement which produces a signal directly proportional to the $\Delta T$, rather than subtracting two values of absolute temperature. This could be done by several methods. The two junctions of a thermocouple (or the two groups of junctions in the case of a thermopile) could measure the $\Delta T$. This way, instead of referencing each thermocouple to a reference temperature, the electric signal is proportional directly to the measured temperature difference. One could also use two closely matched resistance temperature detectors connected in two opposite arms of a resistance bridge to provide a signal proportional to the temperature difference. Finally, two quartz thermometer probes could be used. The output signal is made proportional directly to $\Delta T$ by electronically subtracting the frequency signal of one from the other.

\subsection{Flow measurement considerations}

Equation (1) shows that any error in the measurement of flow rate influence the accuracy of 
determination of $Q$ directly, pointing to the importance of performing accurate flow measurements. The temperature limits of, say, $5-120^{\circ} \mathrm{C}$, the relatively low pressures, and the weak corrosiveness of the fluids do not impose important constraints on most existing flowmeters used in solar heating and cooling (SHAC) systems. However, the relatively low flows incurred, and the wide range of some, create some difficulty in obtaining desirable measurement accuracies. The easiest to measure are constant flow rates, such as obtained with on-off type solar system controllers. On the other hand, variable flow rates are obtained when using proportional controllers or variable demand lines (such as a domestic hot water system). In selecting flowmeters, it is important to distinguish between a flowmeter manufacturer's accuracy specification based on a percentage of the full scale flow range, and that based on a percentage of the actual flow rate.

Furthermore, most flowmeters introduce appreciable pressure drops in the line. This must be taken into account so that (i) adequate pumping head is made available for the desired flow rates, (ii) excessive pumping energy is avoided and (iii) the pressure doesn't drop low enough to induce boiling of hot liquids. Obviously, flowmeters with relatively low pressure drops are desirable for all of the above reasons.

\subsection{Application example}

As a practical example, the design, selection and installation of instrumentation for the University of Pennsylvania SolaRow house is described in Sections 3 to 6 below. This house was retrofitted for both space and domestic hot water heating. The house and its solar energy system are described in detail in Refs. 3 and 4. The system is well-instrumented to achieve the following objectives: (a) to monitor and analyze the performance of the system and its individual components such as collectors, storage, heat exchangers and auxiliary heating units, (b) To optimize the system's performance through appropriate controls, flow rates and thermal storage capacity, (c) To provide hourly weather and insolation data for Philadelphia for a period of at least two years.

These objectives have a wide enough scope to include the monitoring objectives of most other solar heating systems, and the instrumentation guidelines offered here may thus be of general interest. The SolaRow house is in operation and data acquisition is underway.

\section{PERFORMANCE EVALUATION CRITERIA}

The precise definition of the performance evaluation criteria and the equations used to calculate them is a vital prerequisite to any instrumentation system design. After these equations are established, the required measurement accuracy and precision must be defined. Subsequently, a measurement system is designed and implemented to provide the data necessary for the calculation of the performance criteria with the required accuracy and precision. Occasionally, this may be an iterative process, where the initial requirements may need to be relaxed somewhat or otherwise modified to allow for a technically and economically optimal measurement system.

The performance is calculated essentially by equations such as (1)-(3), and detailed descriptions and equations are provided in Refs. 5 and 6 for solar components and in Ref. 7 for solar systems. As an example, the particular performance evaluation criteria for SolaRow, which are to be computed from measured data, include:

(1) savings in fossil fuel

(2) total thermal energy loads

(3) fraction of thermal loads supplied by solar energy

(4) solar system energy conversion efficiency

(5) performance of major components: (a) collectors, with and without partial shading; (b) thermal storage temperature distributions and energy content; (c) operation of the drain-down freeze-protection system; (d) effectiveness of heat exchangers

(6) system use by occupants (demand, temperature, etc.)

(7) operation of the control system

(8) system and component degradation

Additionally, as mentioned above, hourly solar and weather data are collected for this location. 


\section{DATA ACQUISITION}

\subsection{General comments}

Typically, detailed performance monitoring of solar heating and cooling systems requires on the average the measurement of anywhere between 30 and 100 different variables, at typical acquisition intervals of between 2 and 15 min, for at least a full heating and cooling season. Assuming a representative selection of 50 channels at 5-min intervals, 14,400 data points are collected per day, 100,800 per week, and over 2.5 million for a 6 -month season. This massive amount of data precludes manual reduction and analysis and requires the use of automatic data acquisition systems and computerized data storage, reduction and analysis. Three major alternative data acquisition system types can and are being used:

(1) Real-time on-site systems which acquire, analyze and output final results in terms of ready-for-publication tables and graphs. These systems can display on a CRT screen instantaneous results such as total performance parameters or local conditions in different parts of the system. They can provide displays on demand or in a continuous way (see Refs. 8 and 9). This method produces the results in the best way possible, allows immediate recognition of performance trends, simplifies system optimization and trouble-shooting most significantly and reduces in a major way the time and cost required for publication of the results. On the other hand, the system costs are high (typically over $\$ 35,000$ ) because an advanced calculator or more commonly a mini-computer with a large data storage capacity are required. Due to service contract and supervising personnel requirements, the operation cost is also high.

(2) On-site moderate-cost data logger which uses an off-site large computer for practically continuous and simultaneous storage, data analysis and output of results on a time-sharing basis. This system is lowest in cost of the three described and utilizes an existing fully supported and serviced computer facility in an efficient way. Its major disadvantages include the need for an essentially permanent high speed transmission link to the computer. This may be expensive to purchase and maintain. It is also especially vulnerable to the typically long and unpredictable downtimes of most large computer facilities, during which data may be irretrievably lost.

(3) A DAS with sufficiently large storage capacity at the solar installation. The memory storage device, such as a magnetic tape or disk, must be large enough to allow at least several days of unattended data acquisition. This allows relaxation of the supervision schedule for instrumentation personnel without loss of data. The data stored on the magnetic medium is periodically transmitted either manually or via telephone link to a large computer facility for reduction and proper output of results (see Jones ${ }^{19}$ ).

This method has less than half the initial cost of method (1), the system is significantly less expensive to maintain, and is relatively reliable. Its major disadvantage is the lack of real-time results and the relatively long delay between data acquisition and analysis. To alleviate this problem, a system intermediate between (1) and (3) is sometimes used, where an on-site programmable calculator is added to the system of method (3). The calculator performs some of the most important data reduction in real time (see Refs. 11-13). For more detailed analysis, the stored data can still be sent to a large computer.

\subsection{An example: the DAS at SolaRow}

Excluding method (1) due to budget limitations, and method (2) due to its listed disadvantages, method (3) was employed at the SolaRow house. A careful comparative survey of commercially available DASs in this category, all utilizing a microprocessor to perform the data-logging and some amount of data conditioning, indicated that they are basically close in price and performance. All of these systems are flexible in their application, and allow easy changes to their ranges, data acquisition rates, modes of operation and types of measured signals. An 80-channel DAS ${ }^{14}$ was finally chosen because of several distinct advantages over competing systems: (1) Ability to process transient data by means of an inexpensive digital averaging option, as well as by analog signal integration (the latter option may be added later), (2) Ability to scan part of the channels at one rate and another part at a second rate. This allows the scanning (and averaging) of highly transient channels rapidly, and scanning the rest of the channels at a slower rate (and thus increasing MUX switch life), (3) Ability to scan at 10 
channels/sec without being slowed down by the speed of the output peripherals, (4) Reasonable cost, and (5) Good operating experience (information obtained from a number of users).

Options added to the basic system (input ranges: $\pm 40.000 \mathrm{mV}, \pm 400.00 \mathrm{mV}, \pm 4000.0 \mathrm{mV}$ ) included the digital averaging and dual rate scan mentioned, programmable zero offset range, 24 channels of dual setpoint $\mathrm{Hi}$-Lo alarms, and a program bank and memory-save to avoid program and memory loss in case of power failures or system malfunctions.

The system was chosen to provide two simultaneous outputs: one to a magnetic tape recorder, and one to a wide-carriage printer. The printer allows on-site real-time readout of the raw data and serves also as a redundancy backup for the magnetic recorder to achieve improved data acquisition reliability. The printer selected ${ }^{15}$ prints 6 channels of data across the width of the carriage on regular computer paper, at a rate of $30 \mathrm{char}$. $/ \mathrm{sec}$. It was selected in lieu of the standard one channel-per-line printer with which most DASs are equipped because the latter would need 6 times more paper than the former, and does not carry a sufficient supply to record beyond a few hours at the rates needed in most solar systems.

A digital tape recorder ${ }^{16}$ using a $1 / 2$ in wide $1200 \mathrm{ft}$ long standard magnetic tape was chosen for the storage and transfer of data to one of the University's large computers. It has an asynchronous (rather than incremental) drive-motor operation and has a read-after-write check feature. This recorder, it was felt, would provide a superior machine and data reliability, which justifies the somewhat larger cost over incremental digital magnetic tape recorders. Recording at a density of $800 \mathrm{BPI}$, five thousand nine hundred and thirty-two 80-channel, 18-character/channel scans can be recorded on one reel. For one scan each $5 \mathrm{~min}$, one reel would last for about 20 days, but more frequent data reduction would be performed.

The cost of the DAS with the options and the interfaces to the printer and tape recorder was $\$ 10,100 \dagger$. The tape recorder was $\$ 6130$ and the printer $\$ 1650$, for a total system cost of $\$ 17,880$.

To improve data acquisition reliability, elapsed-time meters were installed as a redundancy check to measure the cumulative operating time of the two pumps, the fan, the solenoid valves, the auxiliary furnace's oil burner, and the flow time of gas to the auxiliary gas-fired DHW heater.

\section{SENSOR SELECTION}

\subsection{Temperature measurement}

The measurement of "absolute" temperature in SHAC systems poses no difficulty, and the main emphasis is placed on improving the accuracy of the measurement of the small temperature differences incurred, as discussed in Section 1.3 above.

Careful consideration of the technical and economic aspects of thermometry has resulted in choosing Pt resistance RTDs for this project. The major reason for this choice were: (1) high stability when compared to thermocouples and thermistors, which reduces the frequency of calibration and increases reliability, (2) sufficiently high temperature sensitivity, (3) cost comparable to thermocouples and thermistors. To reduce lead-wire effects and simplify signal conditioning circuitry, the 4-wire constant current (potentiometric) method was chosen for measuring the RTDs resistance. The method is described schematically in Fig. 2.

A constant current of magnitude $i$ is passed through the two current leads of the RTD, and the potential across the RTD is measured between the two potential leads. For large values of

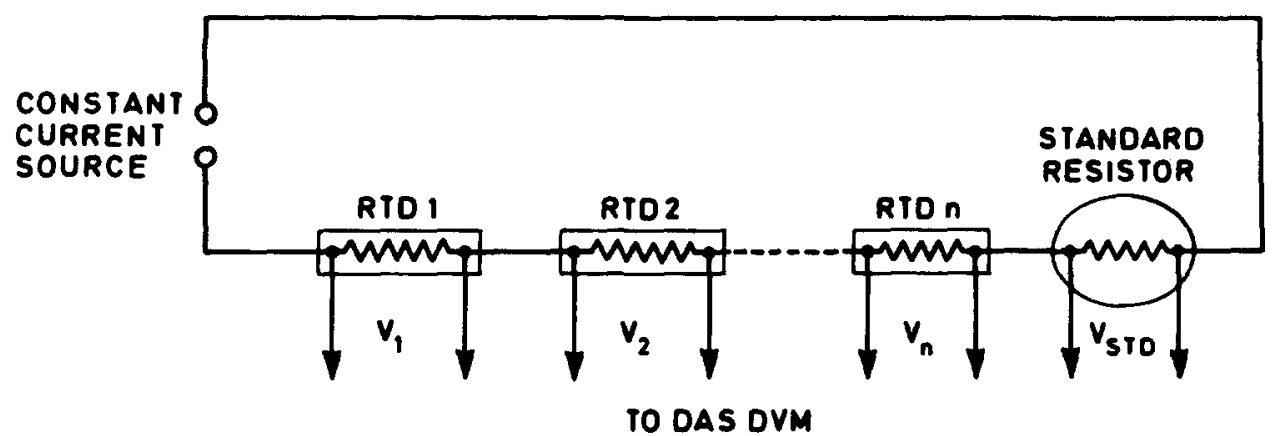

Fig. 2. The potentiometric (constant current) method for measuring resistance.

†All costs are for the year 1978. 
the potential-measuring device's input impedance when compared to the RTDs resistance (say, 1000 fold or more), current flow through the potential leads and their effect on determining the RTDs resistance are negligible. The potential $V$ is linearly proportional to the RTDs resistance, resulting in an output-to-resistance sensitivity equal to $i$, which is double that of a bridge circuit. A number of RTDs can be connected to the same current source in series, and the limit is the maximal resistance which the source can bear without performance degradation, in terms of its compliance voltage, i.e. the compliance voltage must be $\geq$ (current $\times$ maximal resistance). A standard resistor whose resistance is stable and precisely known can be connected in series with the circuit. Reading its potential, $V_{\text {std }}$, allows the determination of the exact value of the current. Nevertheless, the current source should be as stable as possible vs line, load and external environment. ${ }^{17}$ The current source selected for this project is described by Ref. 18. To be able to correct for DAS zero-offset errors in voltage measurement, one of the DAS channels is electrically shorted, and its voltage recorded in each scan.

Requests for specifications and quotations were sent to seven RTD manufacturers. The major specifications obtained were quite similar for all products, but the price ranged from $\$ 41$ to about $\$ 120$ per unit (including weatherproof connector head), in quantity of 51 units. The selected probes were models: R50172-6F100-12 (6 in. long 1/4 in. diameter) and R-50171-24E10012 (24 in. long, $3 / 16$ in. diameter). ${ }^{19}$ The major reasons for selection were: (1) lowest price, (2) specifications comparable to others, (3) RTD pairs matched to the nearest $0.01 \Omega @ 0^{\circ} \mathrm{C}$, (4) the use of resistance temperature elements fully encased in glass to reduce degradation due to environmental effects.

Assuming that self-heating error of $\epsilon_{\mathrm{sh}}\left({ }^{\circ} \mathrm{C}\right)$ is allowed, the maximal sensor current $i_{\max }$ is

$$
i_{\max }=\sqrt{ }\left(\epsilon_{\mathrm{sh}} W_{\min } / R_{\max }\right)
$$

where $W_{\text {min }}$ is the lowest dissipation constant for the RTDs (determined for the least heat dissipative ambient which the probe is to measure) in $\mathrm{mW} /{ }^{\circ} \mathrm{C}$, and $R_{\max }$ is the maximal value of the RTDs resistance. For the RTDs selected, $W_{\min }=18 \mathrm{~mW} /{ }^{\circ} \mathrm{C}$ and $R_{\max }=140 \Omega$. Hence for $\epsilon_{\mathrm{sh}}=0.03^{\circ} \mathrm{C}, i_{\max }=2 \mathrm{~mA}$. The self-heating error would usually be considerably smaller for probes immersed in liquid and operating at these temperatures for which the resistance is below $R_{\max }$. The $2 \mathrm{~mA}$ current allows a temperature resolution of approx. $0.78 \mathrm{mV} /{ }^{\circ} \mathrm{C}$. In the temperature span of interest, of $-40^{\circ} \mathrm{C}$ to $100^{\circ} \mathrm{C}$, the RTD varies in resistance from about 85 to $143 \Omega$, i.e. its output would be $170-286 \mathrm{mV}$. To resolve down to a desired $0.05^{\circ} \mathrm{C}(39 \mu \mathrm{V})$, the

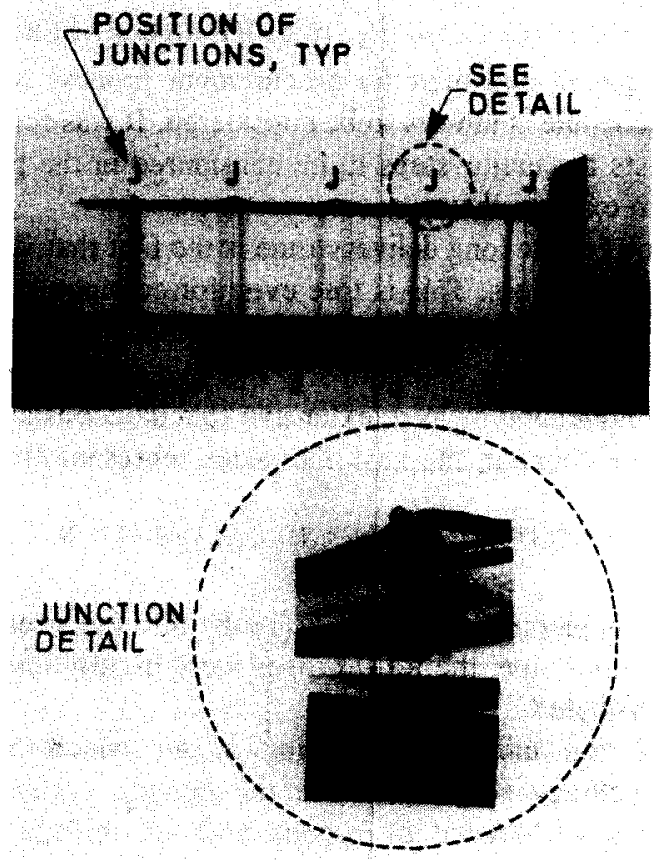

Fig. 3. 10-junction thermopile made for the duct air temperature measurement in the SolaRow House. 
chosen DVM, in which one of the full-scale ranges is $400 \mathrm{mV}$, must be able to resolve approximately one part in 10,000 . The DVM selected for this application has a resolution of $1: 40,000$ and can thus actually provide a sensitivity of $0.012^{\circ} \mathrm{C}$.

Using 20 and 24 AWG wire, two thermopiles were made as recommended by ASHRAE, ${ }^{20}$ one to measure the air temperature difference across the hot water-to-air heat exchanger, and another across the auxiliary warm air furnace. The junctions are supported on a light frame (Fig. 3) which plugs as a unit into the duct through its side. Calibration between two constant temperature baths indicated $\pm 0.02^{\circ} \mathrm{C}$ linearity of the signal up to the $26^{\circ} \mathrm{C}$ difference calibrated. The individual junctions face into the flow and are shielded from radiation by $3 / 4 \mathrm{in}$. long cylindrical reflecting plastic tubes placed concentrically around each junction.

\subsection{Flow measurement}

The flow measurement systems used in this project were selected to provide the performance required at each specific flow line or loop at optimal cost, and are summarized in Table 1.

\subsection{Electric power measurement}

All electric power of significance, consumed by equipment associated with the SHAC system needs to be measured. In this project the power consumed by the solar and demand loop pumps, and the warm air distribution fan are measured by Watt-transducers ${ }^{33}$ which convert the a.c. power to d.c. signals. To minimize starting and stopping transient effects, the voltage leads to each Watt-transducer are connected at the power source, upstream of the equipment's switching device (say motor contactor), while the current leads are connected directly to the equipment. In this fashion, the transducer is continuously powered, but it produces the d.c. signals only when the equipment comes on.

\subsection{Climatological measurements}

For the design or performance monitoring of the SHAC systems, the following typically need to be measured: total insolation, direct (or diffuse) insolation component, ambient temperature, wind velocity, and, in some cases, humidity. These parameters, as well as barometric pressure, are measured at the SolaRow house both to monitor its performance and to provide longer term climatological data of solar engineering interest for the Philadelphia region.

Details on climatological measurements are available in references such as 34-38. The equipment used at SolaRow is described in Table 2.

\section{PROCUREMENT OF EQUIPMENT AND MATERIALS}

The effect of the equipment and material procurement process on the overall manpower expenditure and project schedule is always to be considered. It was found to be very significant in this project. Table 3 lists the major steps to be considered in the procurement process and the average time it took to execute them.

A major obvious reason for the long delivery time is the fact that very few items are kept in stock by manufacturers and vendors. This is true even for common materials such as shielded instrument wire, thermocouple wire, wire terminals, pilot lights, liquid filters, etc. One reason for the long time required to obtain quotations is the fact that the DAS and several of the instruments are relatively novel and/or have extensive specifications and options which require several rounds of communications in the customer-sales representative-manufacturer triangle.

\section{INSTALLATION AND CALIBRATION}

\subsection{Temperature sensors}

To achieve the longest immersion length of the probe into the stream, and low temperature differences between probe and pipe, the RTD probes were usually installed as shown in Fig. 4 and the pipes were well insulated.

The horizontal installation minimizes trapping of air which may accumulate around probes and impair the accuracy severely. Since the heating system in SolaRow is of the drain-down type, it allows withdrawal of probes without spillage, and since the fluid is essentially not corrosive to the stainless steel sheath of the RTD, thermowells were not used. Thermowells may cause severe errors in the measurement of the small and transient tem- 
Table 1. Flow measurement sensors and signal conditioning devices used in SolaRow $\dagger$.

\begin{tabular}{|c|c|c|c|c|c|c|c|c|c|c|}
\hline $\begin{array}{l}\text { Flow } \\
\text { Loop or } \\
\text { Line }\end{array}$ & Fluid & $\begin{array}{l}\text { Maximal } \\
\text { Flow } \\
\text { Rate }\end{array}$ & $\begin{array}{l}\text { Type of } \\
\text { Flowneter }\end{array}$ & $\begin{array}{l}\text { Manu- } \\
\text { facturer } \\
\text { and Model }\end{array}$ & $\begin{array}{l}\text { Flow } \\
\text { Range- } \\
\text { ability }\end{array}$ & $\begin{array}{c}\text { Accuracy } \\
\pm *\end{array}$ & $\begin{array}{l}\text { Maximal } \\
\text { Pressure } \\
\text { Drop }\end{array}$ & $\begin{array}{l}\text { Signal } \\
\text { Conditioning } \\
\text { Instrument }\end{array}$ & $\begin{array}{l}\text { Full } \\
\text { Scale } \\
\text { output } \\
\text { Signal } \\
\text { miv }\end{array}$ & $\begin{array}{l}\text { Total cost } \\
\text { (Flowmeter + } \\
\text { signal } \\
\text { Condjtioner) }\end{array}$ \\
\hline $\begin{array}{l}\text { Solar } \\
\text { collector }\end{array}$ & Water & $\begin{array}{l}14 \mathrm{gpm} \\
(0.88 \mathrm{l} / \mathrm{s})\end{array}$ & Impact & $\begin{array}{l}\text { Ramapo } 21 \\
\text { Mark V-1-J02 }\end{array}$ & $10: 1$ & $\begin{array}{l}0.5 \text { of } \\
\text { Fuili } \\
\text { Scale }\end{array}$ & $\begin{array}{l}4 \mathrm{psi} \\
(27.6 \mathrm{kPa})\end{array}$ & $\begin{array}{l}\text { Ramapo } \\
\text { SGA-100B } \\
\text { Strain- } \\
\text { Gauge } \\
\text { Adapter }\end{array}$ & $10-20$ & $\begin{array}{l}560+ \\
\frac{159}{719} \\
-719\end{array}$ \\
\hline $\begin{array}{l}\text { Space } \\
\text { Heat } \\
\text { Demand }\end{array}$ & Water & $\begin{array}{l}13 \mathrm{gpm} \\
(0.82 \mathrm{l} / \mathrm{s})\end{array}$ & Turbine & $\begin{array}{l}\text { CE Invalco'22 } \\
W 3 / 0750\end{array}$ & 10:1 & $\begin{array}{l}0.5 \text { of } \\
\text { Flow }\end{array}$ & $\begin{array}{l}4.5 \mathrm{psi} \\
(31 \mathrm{kPa})\end{array}$ & $\begin{array}{l}\text { CE Invalco } \\
\text { Flow Rate } \\
\text { Indicator } \\
w-370\end{array}$ & 100 & $\begin{array}{l}218+ \\
=\frac{385}{=} \\
=603\end{array}$ \\
\hline $\begin{array}{l}\text { Domestic } \\
\text { Hot } \\
\text { Water }\end{array}$ & Water & $\begin{array}{l}15 \mathrm{gpm} \\
(0.95 \mathrm{l} / \mathrm{s})\end{array}$ & $\begin{array}{l}\text { Wide-Range } \\
\text { Turbine }\end{array}$ & $\begin{array}{l}\text { Flow Tech- } \\
\text { nology } 23 \\
\text { FT-10N15-LJ }\end{array}$ & $100: 1$ & $\begin{array}{l}0.05 \text { of } \\
\text { Flow }\end{array}$ & $\begin{array}{l}3.3 \mathrm{psi} \\
(22.8 \mathrm{kPa})\end{array}$ & $\begin{array}{l}\text { Flow Tech- } \\
\text { nology, LFA-300 } \\
\text { Range Extending } \\
\text { Amp i, Eier and } \\
\text { Action Pak } 24 \\
5070-8038 \text { ST } \\
\text { Freq. Input } \\
\text { big. Process } \\
\text { Indicator }\end{array}$ & 1000 & $\begin{array}{r}640+ \\
200+ \\
=1165\end{array}$ \\
\hline $\begin{array}{l}\text { Domestic } \\
\text { Hot Water } \\
\text { Tempering }\end{array}$ & Water & $\begin{array}{l}7 \mathrm{gpm} \\
(0.44 \mathrm{\ell} / \mathrm{s})\end{array}$ & $\begin{array}{l}\text { Positive } \\
\text { Displacement } \\
\text { Nutating } \\
\text { Disk }\end{array}$ & $\begin{array}{l}\text { Hersey } 25 \\
\text { MD Metal } \\
0 \text { isc Meter } \\
\text { izluliz2 }\end{array}$ & $14: 1$ & $\begin{array}{l}1.5 \text { of } \\
\text { Flow }\end{array}$ & $\begin{array}{l}2.5 \mathrm{psi} \\
(17.2 \mathrm{kPa})\end{array}$ & $\begin{array}{l}\text { Magnetic Switch } \\
\text { Pulse Generatgro } \\
\text { and Converter } 26\end{array}$ & 4000 & $\begin{array}{r}\quad 60+ \\
=\frac{232}{292}\end{array}$ \\
\hline Warm Air & Air & $\begin{array}{l}1500 \mathrm{cfm} \\
\left(0.7 \mathrm{~m}^{3} / \mathrm{s}\right)\end{array}$ & $\begin{array}{l}\text { Parallel } \\
\text { Multi-Pitot } \\
\text { Tube }\end{array}$ & $\begin{array}{l}\text { Air Moni tor } 27 \\
\text { FAN-E. } \\
\text { W. copper, } \\
\text { sensors }\end{array}$ & $5: 1$ & $\begin{array}{l}\text { loof } \\
\text { Flow }\end{array}$ & $\left(\begin{array}{l}0.04 " \mathrm{~W} . \mathrm{C} . \\
\left(10^{\mathrm{Pa}}\right)\end{array}\right.$ & $\begin{array}{l}\text { Gould } 590-10 \mathrm{~T}- \\
\text { 2Q8-VIX-40 } \\
\text { Integral Barocel } \\
\text { Pressyge Trans- } \\
\text { ducerc8 }\end{array}$ & 10000 & $\underbrace{1124}_{=1270}+$ \\
\hline $\begin{array}{l}\text { Fuel oil } \\
\text { to Furnace }\end{array}$ & $\begin{array}{l}\text { Fuel } 011 \\
\# 2\end{array}$ & $\begin{array}{l}6 \mathrm{gph} \\
\left(0.1 \mathrm{~cm}^{3} / \mathrm{s}\right)\end{array}$ & $\begin{array}{l}\text { Positive } \\
\text { Displacement } \\
\text { (4 radial) } \\
\text { pistons })\end{array}$ & $\begin{array}{l}\text { Coname ter } \\
13-101\end{array}$ & $40: 1$ & $\begin{array}{l}\text { lof } \\
\text { Flow }\end{array}$ & $\begin{array}{l}20^{\prime \prime} \mathrm{W.C} . \\
(5 \mathrm{kPa})\end{array}$ & $\begin{array}{l}\text { Internal } \\
\text { Tachometer }\end{array}$ & 1000 & 710 \\
\hline $\begin{array}{l}\text { Gas to } \\
\text { Domestic } \\
\text { Hot water } \\
\text { Heater }\end{array}$ & $\begin{array}{l}\text { Natural } \\
\text { Gas }\end{array}$ & $\begin{array}{l}175 \mathrm{cfh} \\
(1.38 \mathrm{l} / \mathrm{s})\end{array}$ & $\begin{array}{l}\text { Positive } \\
\text { displacement } \\
\text { (bellows) } \\
\text { integrating } \\
\text { indicator }\end{array}$ & $\begin{array}{l}\text { Ameriçan } \\
\text { Meter } \\
\text { AL-175 }\end{array}$ & $100: 1$ & $\begin{array}{l}\text { lof } \\
\text { flow }\end{array}$ & $\begin{array}{l}0.5^{\prime \prime} \mathrm{W.C} \\
(0.12 \mathrm{kPa})\end{array}$ & $\begin{array}{l}\text { Pulse } \\
\text { Generator }{ }^{31} \\
\text { Converter } 26\end{array}$ & 4000 & $\begin{array}{r}76+ \\
175+ \\
=232 \\
=483\end{array}$ \\
\hline $\begin{array}{l}\text { Collector, } \\
\text { Demand, } \\
\text { DHW } \\
\text { (Balanc- } \\
\text { ing Oniy) }\end{array}$ & Water & $\begin{array}{l}10 \mathrm{gpm} \\
(0.63 \mathrm{l} / \mathrm{s})\end{array}$ & Impact & $\begin{array}{l}\text { Bell } \\
\text { Gossett } 32 \\
\text { Thermoflo } \\
\text { Balancer } \\
\text { TB-1" }\end{array}$ & $5: 1$ & $\begin{array}{l}10 \text { of } \\
\text { Full } \\
\text { Scale }\end{array}$ & $\begin{array}{l}2.8 \mathrm{psi} \\
(13.9 \mathrm{kPa})\end{array}$ & None & $\begin{array}{l}\text { None } \\
\text { (Indi- } \\
\text { cator } \\
\text { onfy) }\end{array}$ & 23 \\
\hline
\end{tabular}

the listing of specific manufacturers and product names in this paper does not imply their endorsement by the author or the study's sponsors. They are provided mainly as a more comprehensive description of the equipment. 
Table 2. Instruments used at the SolaRow house for measuring climatological parameters.

\begin{tabular}{|c|c|c|c|}
\hline $\begin{array}{c}\text { Climatological } \\
\text { Parameter }\end{array}$ & $\begin{array}{l}\text { Type of } \\
\text { Instrument Used }\end{array}$ & $\begin{array}{l}\text { Model, } \\
\text { Manufacturer } \\
\text { and cost } \\
\text { Reference } \mathrm{No:}\end{array}$ & Installation \\
\hline \multicolumn{4}{|l|}{ Insolation: } \\
\hline Total & $\begin{array}{l}\text { Thermopile } \\
\text { Pyranome ter }\end{array}$ & 39 & $\begin{array}{l}\text { In a plane parallel to, } \\
\& 4 "(10 \mathrm{~cm}) \text { above, } \\
\text { collectors }\end{array}$ \\
\hline Direct & $\begin{array}{l}\text { Thernoplle } \\
\text { Pyranometer } \\
\text { with shadow } \\
\text { bond }\end{array}$ & 40 & $\begin{array}{l}\text { In a plane parallel to } \\
\text { and } 15^{*}(-38 \mathrm{~cm}) \text { above } \\
\text { collectors" }\end{array}$ \\
\hline Ambient & $100 \Omega \mathrm{Pt}$ & 41 & \\
\hline Temperature & RTD & & $\begin{array}{l}\text { In an aspirated } \\
\text { radiation shield, } \\
1.5 \text { m above the }\end{array}$ \\
\hline Humidity & $\begin{array}{l}\text { Solid State } \\
\text { (Capacitive) } \\
\text { Relative } \\
\text { Humidity Sensor } \\
\end{array}$ & 43 & $\begin{array}{l}\text { roof with the } \\
\text { collectors }\end{array}$ \\
\hline $\begin{array}{l}\text { Wind Velocity } \\
\text { and Direction }\end{array}$ & $\begin{array}{l}\text { UVW Propeller } \\
\text { Anemometert }\end{array}$ & 44 & $\begin{array}{l}\text { Adjustable height on } \\
10 \mathrm{ft}(3 \mathrm{~m}) \text { high (above } \\
\text { roof), } 2^{\prime \prime} \text { pole. Canti- } \\
\text { levered } 5 \mathrm{ft}(1.5 \mathrm{~m}) \text { away } \\
\text { from pole. } \$\end{array}$ \\
\hline $\begin{array}{l}\text { Barometric } \\
\text { Pressure }\end{array}$ & $\begin{array}{l}\text { Potentiometric } \\
\text { Anerotd }\end{array}$ & 45 & 1 m above roof \\
\hline
\end{tabular}

tThe shadow band stand was for use with a horizontal pyranometer at latitudes of $0-60^{\circ}$. In the present application, at the Philadelphia latitude of $40^{\circ}$, the pyranometer is placed parallel to the collector plane, i.e. at $55^{\circ}$ to the horizontal. Referring to the angle markings on the latitude-setting plate, a $\left(-15^{\circ}\right)$ angle had thus to be attained, which goes beyond the $0-60^{\circ}$ available adjustment range. This was obtained by switching the positions of the two latitude-setting plates and subsequently elevating the centre latitude-setting assembly (with shadow band) 2 in. above its original position with spacers.

\$This instrument is made of three propellers orthogonal to each other, two in the horizontal plane and one in the vertical. They measure the three cartesian components, $u, v, w$ of the wind velocity vector. This type of unit was selected because 3-dimensional measurement of the wind velocity was needed for a number of other related research projects and the standard wind anemometers (such as cup and vane) provide only a 2-dimensional wind measurement.

\$It is important to construct a stable support structure for the wind anemometer to avoid wind induced vibrations of the whole unit and consequent measurement errors.

Table 3. Procurement schedule for equipment and materials.

\begin{tabular}{|c|l|c|}
\hline $\begin{array}{c}\text { Step } \\
\text { No. }\end{array}$ & Procurement Action & $\begin{array}{c}\text { Average Time } \\
\text { Expended, Weeks }\end{array}$ \\
\hline 1 & $\begin{array}{l}\text { Wait for quotations after RFQ's } \\
\text { issued } \\
\text { Make choice of vendor, issue } \\
\text { purchase order } \\
\text { Wait for Delivery } \\
\text { Major equipment and instruments } \\
\text { Materials } \\
\text { Checkout of delivered equipment, } \\
\text { occasional returns because wrong or } \\
\text { faulty equipment was delivered }\end{array}$ & 3 \\
\hline $\begin{array}{l}\text { Total average procurement time; } \\
\text { from issuance of RFQ's until the right } \\
\text { equipment was at hand. }\end{array}$ & 3 \\
\hline
\end{tabular}

$\uparrow$ Request for quotations. 


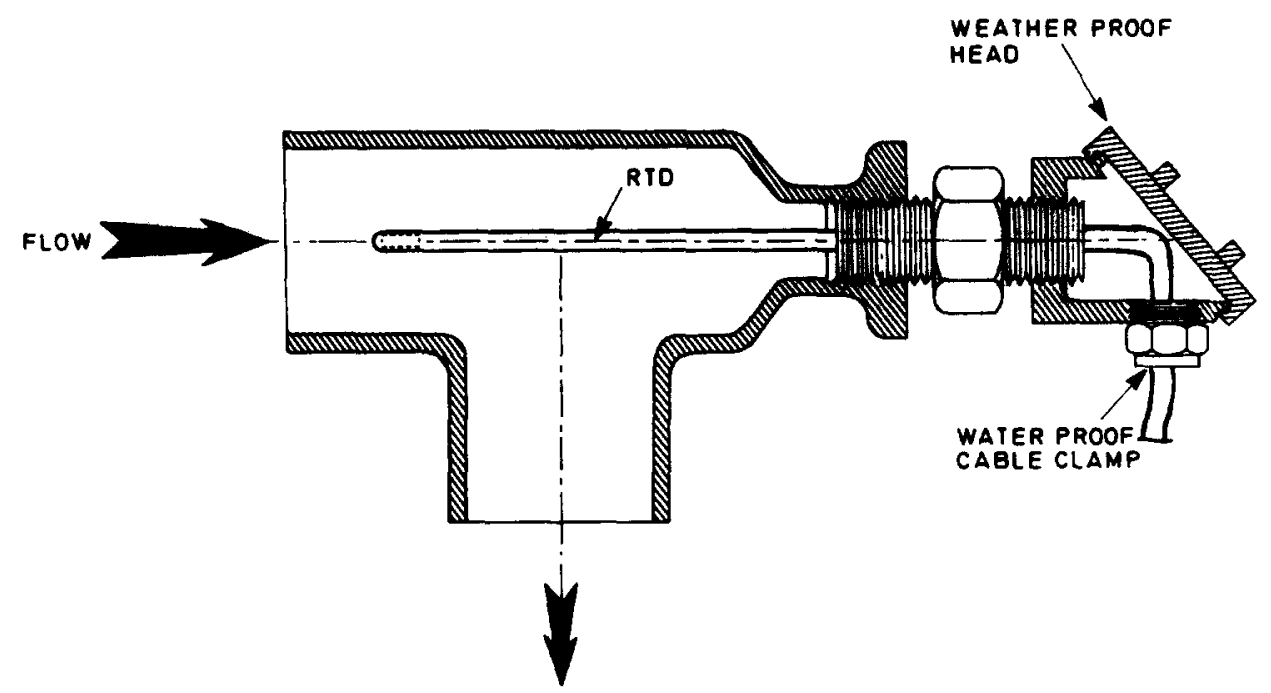

Fig. 4. Typical installation of RTD's in the SolaRow House. The pipes are thermally lagged up to the connector head.

perature differences incurred in solar heating and cooling systems. In spite of some advantages, they should therefore be avoided if at all possible. If thermowells are used, good thermal contact between them and the probes should be insured by having a thermally conductive liquid in the well and/or by bottoming the probe in the well (say, by spring loading or shimming).

To improve the heat transfer coefficient between the probe and the water, the flow passage around the probe could be restricted to generate higher fluid velocity. Another possibility is to generate turbulence around the probe by having flow direction changes, (say, a double $90^{\circ}$ bend) or inserts upstream of the probe. These methods must, however, be considered carefully in view of their negative influence on overall pumping power when many probes are utilized.

The mechanical installation should not generate stresses on the sensitive elements. The probes and their wires should also not be mounted on vibrating surfaces.

The installation must insure that moisture doesn't penetrate to the probe's electric terminals. Weatherproof connector heads are highly recommended for that purpose and for simplified wiring. The wire must also be protected from the environment and should have high grade insulation to prevent short circuits or unwanted ground connections due to penetration of moisture or other degradation.

\subsection{Flow meters}

Several installation guidelines are common to most flow meters: (1) liquid flow meters should always be kept full of liquid by proper location and orientation relative to the rest of the system, (2) evaporation of cavitation in the meter must be avoided by maintaining a sufficiently high pressure, typically by means of a downstream flow regulation valve, (3) proper upstream filtering of the liquid is a must for flow meters which have rotating parts, (4) gas dissolved in the metered liquid introduces measurement errors and should be eliminated, typically by an upstream "air eliminator" which contains an automatic air vent, (5) a bypass line to the flow meter should always be installed to allow the removal of the meter without process interruption, (6) most meters require flow-straightening pipe sections upstream and downstream.

An installation method such as described in Fig. 5 is recommended. It incorporates the bypass and piping unions for the convenient removal of the whole metering section which includes the filter, gas (air) vent, flow meter, and appropriate flow straightening lengths $\left(L_{1}\right.$ and $L_{2}$ in Fig. 5) of pipe. In this fashion, the whole section can also be installed in a separate flow calibration facility, where the flow meter can be calibrated with minimal change to the hydrodynamics of its actual operational conditions.

\subsection{The DAS}

The DAS must be installed in an ambient which does not exceed the temperature and humidity limits allowed by the system's accuracy and operational requirements. Careful attention must be paid to proper shielding and other protection from electrical noise, details of 


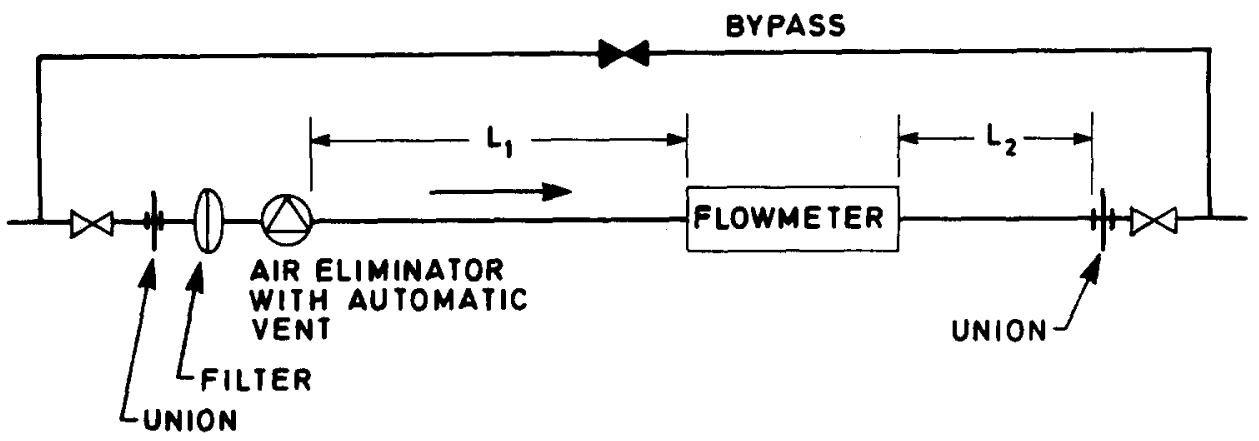

Fig. 5. Recommended installation of flow meters.

which are usually described in the DAS manuals as well as in the general measurements literature. ${ }^{46}$

\subsection{Calibration}

The periodic calibration of all sensors and measurement equipment is absolutely necessary. Ideally, the calibration should be performed in situ, with the sensor or instrument in its normal operating location, using the same wiring, readout and recording instruments employed during normal operation. This method minimizes the influence of the calibration procedure on the characteristic measurements obtained by the calibrated device. For temperature sensors, a reference (standard or secondary standard) thermometer would be brought into intimate proximity with the calibrated thermometer through some access fitting. For flow meters, the flow could be diverted to a volumetric or gravimetric tank and timed, if a sufficient fluid supply is available. Alternatively, a calibrated secondary (or "transfer") standard flow meter can be installed in series with the primary meter, provided mutual flow interference is avoided.

Although in-situ sensor calibration is feasible by providing proper access fittings in the system, it is somewhat complex, reduces the reliability of the main system, and is expensive and time-consuming when many probes need to be calibrated. The second best method is to withdraw the sensors from their location and, in the case of temperature sensors, calibrate them simultaneously in a constant temperature bath while still using the same extension wire and readout system. Flow meters may have to be calibrated at an off-site flow calibration facility.

Additional information on sensor installation can be found in Refs. 5, 6 and 47-59.

Acknowledgements-This study was supported by the USDOE Solar Heating and Cooling R \& D Branch. Some funds for instrumentation were provided by the Pennsylvania Science and Engineering Foundation and by the University of Pennsylvania.

\section{REFERENCES}

1. A. E. Scovill and D. A. Gillett, Proc. USDOE Conf. on Performance Monitoring Techniques for Evaluation of Solar Heating and Cooling Systems, p. 35, Washington, D.C., 3-4 April (1978), Document CONF-780432, NTIS, U.S. Department of Commerce, Springfield, VA 22161.

2. L. J. Murphy, Proc. USDOE Conf. on Performance Monitoring Techniques for Evaluation of Solar Heating and Cooling Systems, p. 7. Washington, D.C., 3-4 April (1978), Document CONF-780432, NTIS, U.S. Department of Commerce, Springfield, VA 22161.

3. N. Lior, J. A. Lepore, and S. Shore, Proc. Joint Conf. of AS/ISES and SESC, Winnipeg, Canada, Aug. (1976), AS/ISES, Inc., American Technological University, P. O. Box 1416, Killeen, TX 76541.

4. N. Lior, S. Shore, J. A. Lepore, and G. F. Jones, Proc. ASIISES Annual Meeting, Denver, Colorado, 28-31 Aug. (1978), AS/ISES Inc., American Technological University, P.O. Box 1416, Killeen, TX 76541.

5. ASHRAE, Methods of testing to determine the thermal performance of solar collectors. ASHRAE Standard 93-77, ANSI B198.1-1977, ASHRAE, 345 East 47 St., New York, NY 10017, Feb. (1977).

6. ASHRAE, Methods of testing thermal storage devices based on thermal performance. ASHRAE Standard 93-77, ANSI B199.1-1977, ASHRAE, 345 East 47 St., New York, NY 10017, Feb. (1977).

7. E. Streed et al., Thermal data requirements and performance evaluation procedures for the national solar heating and cooling demonstration program. Publication NBSIR 76-1137, National Bureau of Standards, Washington, D.C. 20234, Aug. (1976).

8. M. A. Trump, Proc. USDOE Conf. on Performance Monitoring Techniques for Evaluation of Solar Heating and Cooling Systems, p. 69, Washington, D.C., 3-4 April (1978), Document CONF-780432, NTIS, U.S. Department of Commerce, Springfield, VA 22161.

9. H. S. Murray and J. C. Hedstrom, op. cit., p. 75. 
10. D. E. Jones, op. cit., p. 105.

11. J. I. Craig and J. R. Williams, op. cit., p. 139.

12. D. McLenahan, op. cit., p. 163.

13. J. C. Hedstrom, op. cit., p. 229.

14. Model PD2064, Esterline Angus Instrument Corp., P.O. Box 24000, Indianapolis, IN 46224.

15. LA 36 DEC Writer II, Digital Equipment Corp., Maynard, MA 01754.

16. Model 9832-9, Kennedy Co., 540 Woodbury Rd., Altadena, CA 91001.

17. L. Brown, Use of constant current supplies in control instrumentation. Control Engineering, Feb. (1975).

18. Model 7208 (Special), Calex Manufacturing Company, Inc., 3305 Vincent Road, Pleasant Hill, CA 94523. Cost: \$241 each.

19. ARi Industries, Inc., 9000 King Street, Franklin Park, IL 60131.

20. ASHRAE, Standard measurements guide: section on temperature measurement. Standard 41.4, ASHRAE NY, March (1974).

21. Ramapo Instrument Co., Inc., P.O. Box 428, Montville, NJ 07045.

22. C. E. Invalco, Tulsa, OK 74101.

23. Flow Technology, Inc., P.O. Box 21346, Phoenix, AZ 85036.

24. Action Instruments Co., Inc., 8601 Aero Drive, San Diego, CA 92123.

25. Hersey Products, Inc., Old Valley Falls Rd., Spartansburg, SC 29303.

26. MODEL PTA-4050 Pulse Accumulator to Analog Converter, AGM Electronics, Inc., P.O. Box 60089, Tucson, AZ 85733.

27. Air Monitor Corp., P. O. Box 6358, Coddingtown Station, Santa Rosa, CA 95406 ,

28. Gould Inc., 340 Fordham Rd., Wilmington, MA 01887.

29. Conameter Corp., P. O. Box 383, Haddonfield, NJ 08033.

30. Singer, American Meter Division, 13500 Philmont Ave., Philadelphia, PA 19116.

31. Model 821-125-OALP, Rotaswitch Incremental Shaft Encoder, Disc Instruments, Inc., 102 E. Baker St., Costa Mesa, CA 92626.

32. Bell \& Gossett, Morton Grove, IL 60053.

33. Model Halltiplier No. 2100, Scientific Columbus Co., Columbus, Ohio.

34. U.S. Weather Bureau, Manual of radiation observations. Superintendent of Documents, U.S. Government Printing Office, Washington, D.C. 20402, July (1962).

34. World Meteorological Organization, Guide to Meterological Instrumentation and Observing Practices, 4th Edn, Geneva, Switzerland (1971).

36. U.S. National Weather Service, Observing Handbook No. 3, Solar Radiation Observations. U.S. Department of Commerce, NOAA, NWS, Silver Spring, MD 20907, March (1977).

37. U.S. Weather Bureau, Instruments for Climatological Observations, Circular B, 11th Edn. Superintendent of Documents, U.S. Government Printing Office, Washington, D.C. 20402, Jan. (1962)

38. U.S. NOAA (with DOD and DOT), Federal Meteonological Handbook No. 1-Surface Observations, Change 3. Superintendent of Documents, U.S. Government Printing Office, Washington, D.C. 20402, 1 July (1975).

39. Model PSP Pyranometer, The Eppley Laboratory Inc., Newport, RI 02840, Cost $\$ 990$.

40. Model PSP Pyranometer with Shadow Band, The Eppley Laboratory, Inc. Newport, RI 02840, Cost: \$1690.

41. Model RS0172-6F100-12, Ref. 19.

42. Model IS6-RH-FD Motor Aspirated Radiation Shield with Fan Failure Alarm, Weather Measure Corp., P.O. Box 41257, Sacramento, CA 95841, Cost: \$400.

43. Model HM-111-C, Weather Measure Corp., P.0. Box 41257, Sacramento, CA 95841, Cost: $\$ 772$.

44. Model 27004 Gill UVW Anemometer w. $19 \mathrm{~cm}$ propellers, and w. Model 27503R Indicator-Translator, R. M. Young Co., 2801 Aero-Park Dr., Traverse City, Mich. 4\%844. Total Cost: \$1487.

45. Model 2014-27/315 HA-3-WH Yellow Springs Instrument Co., Inc., Yellow Springs, OH 45387. Cost \$450.

46. R. Morrison, Grounding and Shielding Techniques in Instrumentation. Wiley, New York (1967).

47. IBM Corp., Instrumentation installation guidelines. Rep. SOLAR/0001-77/15, USDOE, NTIS, U.S. Department of Commerce, Springfield, VA 22161, 1 Nov. (1977).

48. ASME, PTC 19.3-191, Supplement to power test codes, instruments and apparatus, Part 3: temperature measurement. ASME, 345 East 47 Street, New York, NY 10017 (1961).

49. H. S. Bean [Ed.], Fluid Meters, Their Theory and Application, Report of the ASME Research Committee on Fiuid Meters, 6th Edn, ASME 345 East 47 St., New York, NY 10017 (1971). 